\title{
Examining Tourism Operators' Responses to Environmental Regulation: The Role of Regulatory Perceptions and Relationships
}

\author{
Sally V. Russell \\ UQ Business School, The University of Queensland, \\ Brisbane QLD 4072, Australia \\ George Lafferty \\ Industrial Relations Centre, Victoria University of Wellington, \\ New Zealand

\section{Rebecca Loudoun \\ Griffith Business School, Griffith University, Nathan Campus, Nathan QLD 417 1, Australia}

In this paper we present the findings of a study examining tourism operators' responses to environmental regulation. Using evidence from five case studies in Eastern Australia, we assess how the three variables of the perceptions of environmental regulation, the perceptions of the regulatory agency, and the relationship between the operators and the regulators, can affect the responses of operators in sensitive natural areas. Our findings extend current literature on environmental regulation and highlight how operators' perceptions of environmental regulation significantly influence their responses to regulation. The paper illustrates the need to understand the regulatory relationship from the perspectives of both regulators and tourism operators. It concludes by addressing the practical issue of improving the regulatory relationship and the broader question of the human side of environmental regulation.

doi: $10.2167 /$ cit319.0

Keywords: environmental regulation, perceptions of regulation, perceptions of regulators, regulatory relationships

\section{Introduction}

The tourism industry's relationship to the natural environment is evident as the success or failure of a substantial proportion of the industry hinges on the continued quality of the natural environmental (Allcock et al., 1994; Coen, 2005; Hunter, 1997; Willman et al., 2003). It is also clear that increasing numbers of tourists can have a significant negative effect on the natural environment (Briassoulis \& van der Straaten, 1992; Coen, 2005; Willman et al., 2003). Tourism operators who rely on sensitive natural areas to attract tourists are therefore in a difficult position. On the one hand, operators are dependent on the natural environment to stimulate demand, yet the more demand generated, the greater the potential for environmental damage (Huybers \& Bennett, 1997). 
The debate over the role of government regulation in protecting the natural environment can be considered along a continuum. At one end of this continuum, scholars oppose any type of government imposed regulation and argue that market forces are the most efficient and appropriate means to ensure the continued value of the natural environment as well as ensuring the success of organisations (Gray, 1987; Jaffe et al., 1995). At the opposite end are those who argue that appropriate government imposed regulations have a positive impact on the natural environment and also provide opportunities for proactive organisations to gain a competitive advantage (Knudsen \& Madsen, 2001; Porter \& van der Linde, 1995b). The middle of the continuum is occupied by proponents of a combination of both market mechanisms and government regulation, who consider public-private partnerships and other forms of collaboration between industry and government to be the most appropriate means of conserving the natural environment while also maintaining the viability of firms (Etsy, 1994; Mol et al., 2000).

This paper contributes to this literature by examining environmental regulation with respect to tourism accommodation providers who are operating in sensitive natural environments. Drawing on five case studies in Eastern Australia, we argue that the human side of regulation is an important dimension that is often overlooked in the debate around the efficacy of environmental regulation. Our findings specifically suggest that management perceptions of both the regulation and the regulatory agency, in conjunction with the relationship between the operator and the regulators, constitute important dimensions influencing organisational behaviour in response to environmental regulation. In the following sections, we briefly describe key elements around the contentious issue of environmental regulation and current research investigating this issue in a tourism context. We also discuss literature indicating the importance of the human dimension of environmental regulation, particularly how management perceptions and the regulatory relationship can influence organisational responses to environmental regulations.

\section{Environmental Regulation}

Scholars who argue against government regulations often do so from the neo-classical economic assumption that markets are always superior (Weitzman, 1974). Proponents of this perspective argue that environmental regulations are in conflict with the goals of the firm (e.g. Gray, 1987; Jaffe et al., 1995). A general assertion in this stream of literature is that the purpose of environmental regulation is to internalise the costs of pollution, which are usually borne by the public. The price of environmental degradation is therefore attributed to the firms responsible for it (Maxwell, 1996).

Many authors within this area maintain that when firms change their operations in response to environmental regulations, they often introduce less efficient practices (Jaffe et al., 1995), resulting in a less efficient and therefore a less profitable firm (Gray, 1987). It is also asserted that using a firm's valuable resources in environmental projects results in their withdrawal from more rewarding and efficient applications (Gray, 1987). Additionally, lengthy permit-acquiring processes are said to add to any inefficiencies (Barbera \& McConnell, 1990). 
The argument follows that organisational self-regulation will effectively ensure that the natural environment is protected. For example, Wells (1994) argues that it is managements' responsibility to find ways of balancing environmental and financial goals. Furthermore, he suggests that responsibility for environmental management should not fall to government or an external regulatory agency, but rather that the firm should take on this responsibility. However, others argue that self-regulation alone will not be sufficient to ensure the protection of the natural environment (Fineman, 1998; Porter \& van der Linde, 1995a).

Scholars such as Porter and van der Linde (1995a, 1995b), Rosen (2001) and Knudsen and Madsen (2001) make the argument that organisations can develop a competitive advantage by using an environmental strategy in response to environmental regulation. This argument is strongly tied to the resource-based view of the firm (Hart, 1995, 2000; Rosen, 2001). Proponents of this view argue that valuable, costly-to-copy firm resources and capabilities provide the key sources of competitive advantage (Hart, 1995). The right type of environmental regulation can therefore encourage firms to innovate in order to lower the total cost of a product or to improve its value. Such innovations allow companies to use a range of inputs more productively, thereby offsetting the costs of reducing environmental impacts and ending the apparent trade-off between profitability and environmental change (Hunt \& Raman, 2000; Knudsen \& Madsen, 2001; Majumdar \& Marcus, 2001; Porter \& van der Linde, 1995a).

According to Porter and van der Linde (1995a), regulation is necessary but should also be sufficiently flexible to allow ample time to develop new means and to phase in new technologies. Additionally, regulation needs to impose challenging performance goals to create pressures for efficiency (Majumdar, 1997; Porter \& van der Linde, 1995a). Research by Majumdar and Marcus (2001) into electrical utilities adds empirical support to Porter and van der Linde's (1995b) thesis. Their study found that flexible regulation resulted in significant productivity increases, whereas excessively rigid regulation decreased productivity.

Other researchers, such as Gray (1994), argue that the conflict between industrial and environmental performance should not necessarily be viewed as a problem. Gray gives examples of managers (from organisations such as British Telecom and the Body Shop) who have internalised the view that this conflict is necessary to allow sustainable development at the macro level (Gray, 1994). However, this perspective contrasts with that of Etsy (1994) who argues that command-and-control type regulation is ill-conceived and that appropriate flexible, market-based incentives would be more effective in allowing organisations to integrate environmental excellence into their business strategy. Although debate continues as to whether command-and-control or flexible approaches are more effective, these scholars agree that regulation is necessary to ensure the protection of the natural environment while maintaining firm performance.

Within this debate, there are also those who argue for a combination of both regulation and market mechanisms, or joint environmental policy-making. Joint policy making proposes solutions that differ from regulation or market mechanisms in that joint initiatives aim to achieve modifications of environmentally destructive behaviours through a process of negotiation and agreement between 
organisations and regulatory agencies (Mol et al., 2000). Whereas joint policy making is largely voluntary, there is a high level of interaction between public and private actors, and it is therefore different from self-regulation.

These differing perspectives suggest that environmental regulation can have a wide variety of impacts and it is often unclear whether economic goals and environmental goals are complementary or conflicting. It is important, therefore, to continue addressing environmental regulation in research, to ensure that knowledge of this phenomenon continues to be developed and moves towards a clearer theoretical and practical conceptualisation of the phenomenon. We now consider this debate within the context of the tourism literature, which is the focus of this paper.

\section{Tourism and Environmental Regulation}

Tourism has been identified as an industry under increasing pressure from governments to become more sustainable (Elkington, 1994). The potential impact of growing numbers of visitors to natural areas has meant that more attention has been directed towards the environmental sustainability of sensitive natural areas (Allcock et al., 1994; Carter et al., 2001; Hunter, 1997; Yunis, 2003). Research has indicated that organisations within close proximity to sensitive natural areas are likely to be those most affected by environmental regulation (Carter et al., 2002, 2004). The role of environmental regulation in the sustainability of tourism, however, is one that is often secondary to other research objectives. Current tourism literature does comment on the character and effects of environmental regulation (Briassoulis, 1995; Goodall et al., 1997; van Fossen \& Lafferty, 2001), yet there is a dearth of research examining regulation directly (Yunis, 2003).

Briassoulis (1995) theoretically considers regulation as part of a larger examination of the internal and external impacts on tourism organisations. He suggests that a combination of planning tools is necessary to achieve environmentally sound and balanced tourism development. Land use planning and regulation are argued to be the most important and widespread mechanisms external to the organisation to control environmental outcomes. He also suggests that the usual prescription by economists, to implement a price mechanism to internalise costs for maintaining environmental sustainability, is inappropriate for the tourism industry due to its complex and multifaceted nature (Briassoulis, 1995). These assertions are yet to be empirically tested.

Van Fossen and Lafferty (2001), in a comparative study of tourism development in Hawaii and Queensland, found that the organisational costs of regulation and government control are more than offset by the benefits accrued by the community and environment. This conclusion supports the findings of Goodall et al. (1997), who maintain that sustainable development of tourism will require command-and-control approaches, such as land use planning, and economic instruments which give both incentives to take action and deterrents to continue damaging activities. Further research is needed in order to test these claims and thereby bring current environmental regulation research into the context of the tourism industry.

The literature reviewed above illustrates how environmental regulation can and does have differing impacts on tourism organisations. Whereas some types 
of regulatory arrangements may be appropriate in one industry or sector, the same approach will not necessarily be effective in others. In this study, our aim was to explore current environmental regulation as it relates to tourism operators in sensitive natural environments. We argue that tourism providers operating in this setting are likely to be significantly affected by environmental regulation, and are also most dependent on the quality of the natural environment for creating tourism demand. In order to explore these issues further, our first research question is:

How do tourism operators in sensitive natural environments respond to environmental regulation?

\section{The Human Side of Environmental Regulation}

The research described thus far has focused on the debate over the efficacy of environmental regulation and the impact this has on the balance between organisational and environmental goals (Jaffe et al., 1995; Porter \& van der Linde, 1995a, 1995b). Other research has also suggested that perceptions of the regulation can have an impact on how organisations respond to environmental regulations. For example, Sánchez (1997) argues that the way managers perceive environmental regulation affects the behaviour of the organisation in response to the regulation. She proposes a positive relationship between the perception of environmental regulation as an opportunity and the extent to which an organisation complies with and exceeds the regulation. This proposition is yet to be empirically tested.

There is also some evidence that this proposition may be relevant to the tourism industry. Huybers and Bennett (1997) surveyed 208 Australian tourism operators, asking them to report on the perceived costs and benefits of self-regulation and government regulation. They argue that if government environmental regulations were perceived to improve profitability of operators, then the regulations would be accepted more readily by industry, thereby enhancing its effectiveness. They found that reported profits were also greater when managers' perceptions of the benefits outweighed the costs associated with regulation.

Huybers and Bennett's (1997) findings provide some support for the theoretical propositions of Sánchez (1997) that managers' perceptions of environmental regulation can influence organisational responses to regulation. However, it has also been suggested that further research is needed to examine this issue in more detail to estimate more precisely how perceptions can affect responses to environmental regulation (Huybers \& Bennett, 1997; Sánchez, 1997). We therefore propose a second research question:

How does the perception of the environmental regulation affect tourism operators' responses to environmental regulation?

In examining the human side of environmental regulation, there is also evidence that the relationship between organisations and government regulators has implications for how organisations might respond to regulation. For example, Fineman's $(1998,1999)$ research suggested that regulation is often ambiguous and emotional for the regulators. He stresses the need for careful management 
of the relationship between the regulator and organisational members, to eliminate ambiguities and ensure that a cooperative relationship between industry and regulatory agencies is maintained.

This regulatory relationship is likely to become even more important as regulation moves towards more flexible approaches (Coen, 2005; Willman et al., 2003), and particularly in joint environmental policy-making. Mol et al. (2000) suggest that joint environmental policy-making has succeeded where the relationship between public and private actors was based on cooperation and consensus. Other research has also found that regulatory relationships based on trust and cooperation can result in less intensive monitoring on the part of the regulator, and a more 'understanding' response to apparent performance lapses (Willman et al., 2003).

Further research, particularly from the perspective of the organisation, is needed to explore these relationships (Fineman, 1998; Willman et al., 2003). Based on this research, we aim to investigate the relationship between tourism operators and the regulatory agency and the impact this has on how the operators respond to environmental regulation. Our third research question is therefore:

How does the relationship between the tourism operator and the regulatory agency affect tourism operators' responses to environmental regulation?

\section{Methodology}

In order to explore tourism operators' responses to environmental regulation, a multiple case study methodology was used. The appropriateness of this methodology was assessed using Yin's (2003) typology for case study research. The first condition is the appropriateness of the research question. Each of the three research questions proposed in this study can be described as 'how' questions. This type of research question is suited to a number of different methods, including a case study design (Yin, 2003). We therefore also considered the second and third conditions in Yin's typology of case study research.

The second condition suggests that a case study design is appropriate where the researcher cannot control behavioural events. The overarching goal of this research project was to examine tourism operators' responses to regulation, and control over behavioural events was therefore low, suggesting a case study methodology would be appropriate.

Finally, Yin suggests that case studies are most appropriate when the focus of the research is on contemporary events. In this research project, the aim was to capture tourism operators' current responses. Based on these criteria, we therefore considered a case study design to be the most appropriate methodology to investigate our research questions. Additionally, previous research had also supported this method and suggested that a case study methodology would be appropriate for studying the effects of environmental regulation on organisations (Briassoulis, 1995; Hunt \& Raman, 2000; Huybers \& Bennett, 1997; Mitchell \& Bernauer, 1998).

Nature-based tourism was selected as the sample for this study. A large proportion of the tourism industry, particularly within Australia, is dependent on the natural environment (Carter et al., 2004; Coen, 2005; Willman et al., 2003). The potential impact of increasing numbers of visitors to natural areas has 
meant that more attention has been directed towards the environmental sustainability of sensitive natural areas (Allcock et al., 1994; Carter et al., 2001, 2004; Hunter, 1997). Research has also suggested that organisations within close proximity to sensitive natural areas are likely to be most effected by environmental regulations (Carter et al., 2004). We therefore considered organisations in this situation to be suited to our research questions.

Five case organisations were selected for this study. All were accommodation providers in close proximity to a World Heritage Listed Site in Eastern Australia. The site was listed under the World Heritage criteria for natural heritage defined in article 2 of the World Heritage Convention (UNESCO, 2002). This listing implies that the site has 'outstanding universal value' for both present and future generations. The location of these organisations meant that they were affected by environmental regulation on a daily basis, and that they were affected by a wider range of environmental regulations than other types of tourism business, such as tour operators (Carter et al., 2004). Data collection included semi-structured interviews with key decision makers, site visits and textual documents.

Each of the semi-structured interviews lasted between 45 and 75 minutes and was conducted during site visits. In three cases, interviews were conducted with operational or environmental managers of the organisations, and in two cases interviews were conducted with owner/managers. Participants were initially asked about the regulations relevant to their organisations and the agencies responsible for maintaining compliance with these regulations. Participants were then asked about their perceptions of the regulations and their relationship with the regulatory agency. The organisational response to the regulation was also investigated within the interviews, but this was also triangulated during the site visits and textual document collection. The types of textual documents collected included information from web pages, policy manuals, training documents, advertising flyers, brochures and industry accreditation applications.

\section{Analysis}

The data were examined in several divergent ways in order to maximise the internal validity of the study and to minimise the danger of reaching premature or false conclusions (Eisenhardt, 1989; Yin, 2003). Analysis began with the transcription of the interviews, allowing the researchers to become familiar with the interview data and to identify areas of importance. Once transcription was complete, the interviews were corroborated with documentary evidence and site visit notes. This enabled the researchers to become familiar with each case as a stand-alone entity and to perform a within-case analysis (Miles \& Huberman, 1984). Data from each case were coded separately using the recommendations of Miles and Huberman (1984). This process allowed the unique patterns of each case to emerge before patterns were generalised across cases (Eisenhardt, 1989).

The next stage of analysis involved the search for patterns and themes (Eisenhardt, 1989; Miles \& Huberman, 1984; Yin, 2003). Data from each case were compared to the other cases to ensure that the data were examined in several divergent ways (Eisenhardt, 1989). Several themes and patterns emerged from this comparison of cases, and these were categorised according to each of the three research questions (Miles \& Huberman, 1984). 


\section{Results}

In presenting the results of this study, the findings relevant to each research question are presented in turn. Research Question 1 asked: How do tourism operators in sensitive natural environments respond to environmental regulation? To answer this research question, the results from each case are presented sequentially, highlighting differences in the responses across the five cases. The second and third research questions concerned the perceptions of the regulation and the relationship between the operator and the regulatory agency. These questions are answered according to the key themes that emerged during the data analysis.

\section{Responses to environmental regulations}

In order to classify the responses of the tourism operators we employed the typologies of Sharma and Vredenburg (1998), Aragón-Correa (1998) and Roome (1992). These typologies classify organisational responses to environmental regulation along a continuum from proactive to reactive. Reactive organisations primarily respond to environmental issues only when required to do so by regulation and the primary focus of the organisation is on compliance (AragónCorrea, 1998; Roome, 1992; Sharma \& Vredenburg, 1998). Reactive organisations can be further classified as 'non-compliant', where they fail to comply with regulatory requirements, or 'compliant', where they comply with, but do not outperform, existing regulations (Aragón-Correa, 1998; Roome, 1992; Sharma \& Vredenburg, 1998).

In contrast, proactive organisations not only comply with regulation but implement initiatives to outperform the regulatory requirements (Sharma \& Vredenburg, 1998). Furthermore, proactive organisations can be classified as either 'compliance plus' or 'leading edge'. Compliance plus organisations take a proactive position in response to environmental regulation and perform beyond the current requirements of the law (Aragón-Correa, 1998; Roome, 1992). Leading edge organisations are even more proactive in their responses to environmental regulation and are categorised as being 'at the leading edge in their sector' and having environmental performance 'which set[s] the standard for other businesses' (Roome, 1992: 19). Based on these typologies, we classified each of the cases into the most appropriate category in responding to environmental regulation.

Case A was an accommodation provider surrounded by the World Heritage area. This organisation was one of the largest in the study, with a capacity of approximately 100 guests. It had a history beginning in the early 1900s and was privately owned with an independent manager charged with the responsibility of overseeing day-to-day operations.

The response to environmental regulation in Case A could be classified as proactive (Sharma \& Vredenburg, 1998) and at the leading edge of environmental performance (Aragón-Correa, 1998; Roome, 1992). There was evidence that this organisation was performing beyond the requirements of the regulation and there was also a strong focus on seeking out opportunities to improve the environmental performance, while also ensuring constant monitoring of compliance. In this case, the motivation for performing beyond compliance was to stay 'one step ahead of the regulations'. 
The organisation was accredited as an 'advanced' ecotourism operator by Ecotourism Australia (the highest of three levels of accreditation), and was also accredited by the Green Globe program. These accreditations were displayed prominently in brochures, on the organisation's website and at the establishment itself. Case A was also part of a partnership program with the state government, which also publicised the organisation's environmental achievements. All three data sources - site visit, textual documents and semi-structured interview - provided evidence of the leading edge proactive response to environmental regulation in Case A.

Case B was also surrounded by the World Heritage area. This accommodation provider was privately owned, and was effectively managed by both the owners and other board members of the organisation. This organisation was the largest organisation in the study, with a capacity of approximately 150 guests. Similar to Case A, this accommodation provider could also be classified as being proactive in response to environmental regulation, and could also be categorised as being leading edge in environmental performance (AragónCorrea, 1998; Roome, 1992).

Case B also held accreditation as an 'advanced' ecotourism operator from Ecotourism Australia (the highest of three levels of accreditation), and this was noted in brochures as well as on the organisation's website. There was evidence that continuous improvement was the aim and that best practice environmental initiatives had been implemented widely across the organisation. There was also a focus on sharing knowledge with other organisations in close proximity to the sensitive natural area, to ensure environmental conservation. In contrast to Case A, there was more of a laissez-faire attitude towards environmental regulations, and aiming for environmental best practice was considered the right thing to do', rather than the proactive response being motivated by existing or possible future regulations.

The third case, Case C, was a medium sized accommodation provider, with a maximum capacity of approximately 35 guests. The property was privately owned, with two manager/caretakers responsible for the management and day-to-day operations of the organisation. The property bordered the World Heritage area on three sides, and was a more recent operation, established in the late 1990s.

The data suggested that, in Case $C$, the organisational response to regulation could be categorised as reactive (Sharma \& Vredenburg, 1998) and noncompliant (Aragón-Correa, 1998; Roome, 1992). Evidence from the interview with the manager, textual documents and the site visit demonstrated that the focus of the organisation was firmly on complying with environmental regulations, although it was also evident that the organisation was struggling to achieve this goal. In fact, there was evidence that the managers had attempted to avoid reporting non-compliance in order to avoid any associated penalties. Although the organisation was involved in interpretation of the natural environment for visitors, it was within the reactive category in terms of responding to environmental regulations.

In both Cases $\mathrm{A}$ and $\mathrm{B}$, there was evidence that the environmental performance was used as a marketing tool on websites and in brochures. This was not evident in Case C. In fact, the marketing documents for Case $C$ heralded the 
significant natural beauty in the surrounding World Heritage site, but did not mention the environmental performance of the organisation in any form.

Case D was a smaller accommodation provider, with a capacity of approximately 40 guests. It was situated 500 metres from the World Heritage area and was established in the early 1990s. This accommodation provider was an owner/manager operation and was accredited by Ecotourism Australia as an 'ecotourism' operation (the middle of three levels of accreditation). The evidence suggested that the response to the regulation was proactive (Sharma \& Vredenburg, 1998), yet not to the same extent as Cases A and B. This operator could be classified as a 'compliance-plus' organisation (Aragón-Correa, 1998; Roome, 1992), as efforts were being made to continually improve environmental performance, but this was not a primary focus for the organisation.

Case E was a similar organisation to Case D. Established in the early 1990s, it was a small accommodation provider, with a maximum capacity of 30 guests. The property was bordered on one side by the World Heritage area and was an owner/manager operation. This organisation was accredited by Ecotourism Australia as a 'nature tourism' operator (the lowest of three levels of accreditation). The response to environmental regulation in this case was similar to that in Case D. Although there was a proactive response to the regulation and the operator was performing beyond compliance, this was not to the same level of best practice as was demonstrated in Cases A and B. This case could therefore be classified as proactive (Sharma \& Vredenburg, 1998) and also within the 'compliance-plus' category (Aragón-Correa, 1998; Roome, 1992).

The evidence from these five cases suggests that there were differences across the cases as to the organisational response to environmental regulations. These responses varied along the continuum from a reactive response of noncompliance to the most proactive response of leading edge environmental performance (Aragón-Correa, 1998; Roome, 1992; Sharma \& Vredenburg, 1998). In the next section, we examine the results from research questions two and three, with a focus on the human side of environmental regulation.

\section{Management perception of regulations}

The management perceptions of the environmental regulations were generally reflected through the interviews with managers from each of the cases. These interviews revealed differing perspectives, which we found had an impact on how the organisation responded to the environmental regulation.

The main regulations discussed by participants related to wastewater management, tree management and solid waste management. In all cases, tree management and solid waste management regulations were perceived positively, with the outcomes being uncomplicated and negotiable. All participants described this approach as allowing cooperation between operator and regulator. Findings in relation to wastewater regulations were less straightforward. Respondents gave these regulations, all monitored by the Environmental Protection Authority (EPA), the greatest attention.

All organisations in the study had wastewater treatment plants; they were therefore subject to state level Waste Management Regulations, specifically the Queensland Environmental Protection Act 1994. The organisations were also subject to both national and state-level legislation, from both the Australian 
Commonwealth Environment Protection and Biodiversity Conservation Act 1999 and the Queensland Nature Conservation Act 1992 relating to contamination of water in a World Heritage Site.

Management perceptions of the regulations varied across the cases. In Cases $\mathrm{A}$ and $\mathrm{B}$ the perception of the regulation was generally positive. In Case $\mathrm{A}$, the manager stated that regulation was a strict but positive force in driving the organisation's environmental goals, and did not suggest this was too onerous for the organisation:

If you're treating your own effluent there are some very strict guidelines with the EPA in relation to final effluent quality. So we have [...] fairly stringent rules in respect to how we test that final effluent. (Case A)

The manager of Case A also suggested that more regulation was necessary and stated that in relation to tourism generally, 'it is all becoming more regulatory as the years go by and I think it's necessary that this happens'.

Although the manager in Case B had the perception that regulation could be a positive motivator for improving environmental performance, there was also a perception that the regulation was onerous on businesses. Regulations were considered to 'hang over the business', and it was also suggested that 'the licence conditions [for wastewater treatment] are in some instances a bit onerous'.

Despite this perception of the regulation as onerous, there was also a perception in Case B that the regulations were flexible in managing compliance. An example was given where the manager of the organisation in Case B had reported their non-compliance to the EPA and in doing so received assistance and advice in order to minimise the potential impact on the environment:

When you put your annual report in, some months later you get a letter saying, 'You're not complying, we're going to send up some compliance officers'. But the compliance officers were pretty reasonable, in that they were discussing with people what they thought was the best approach and I thought that was good. (Case B)

The perception of the regulation in Case $C$ differed in that the perception was particularly negative. The regulations were considered to be too onerous on the organisation, both in terms of time and financial costs. The manager of Case C questioned whether they would have established an effluent treatment plant at all, had they been fully aware of the regulatory requirements:

You know you have to ask the question now, 'Would I do it again?' because it is extremely expensive ... and as I say if we were actually doing everything we were supposed to be doing you would really have to ask 'Can you do that? 'Can you really be committed to doing all of that?' And that's my concern. It's that people are put off because there's just so much that goes along with it. (Case C)

There was also evidence that the manager in Case $C$ had a strong fear of retribution for failure to comply with the regulations. In contrast to Case B, where the manager worked with the EPA to ensure compliance, in Case C noncompliance was not reported: 
We didn't send in a report [...] I was reluctant to ring the EPA because I thought I don't really want to bring them down on me because [we] haven't done the right thing. (Case C)

The perceptions of environmental regulation in both Cases D and E reflected no strong positive or negative views. The perception was more ambivalent and the regulations were not considered to be particularly onerous on the organisation and therefore not a major concern. It was suggested that compliance was achieved through 'testing four times a year' and this was not considered onerous for either organisation. The manager in Case D suggested that the regulations were not policed particularly strongly in stating that 'They [the EPA] don't have checks on [us] ...'.

Whereas our second research question concerned perceptions of the environmental regulation, we also found a recurrent theme in perceptions of the regulatory agency. We considered this theme separately, as it was most often discussed apart from the perceptions of the regulation.

\section{Management perception of the regulatory agency}

The Environmental Protection Agency (EPA) and Queensland Parks and Wildlife Service (QPWS) were the two regulatory agencies monitoring compliance with the environmental legislation and regulation for the case organisations in our study. Although the QPWS technically forms a department of the EPA, they were treated as separate organisations in the research study, reflecting their respective roles of monitoring and compliance that are quite different and separate from each other in practice. For example, the main concern of QPWS rangers is the local area within their jurisdiction, whereas the EPA is involved in monitoring and overseeing compliance of state-wide legislation and regulation.

\section{Environmental Protection Agency}

There was a general perception in Cases A and B that the EPA had the power to enforce regulations with prosecutions, fines and permit withdrawal, and that this was a motivating factor for compliance:

Because they've got the big stick there, the fact that they haven't used it probably doesn't matter, it's still encouraging people [...]. (Case B)

If you're not demonstrating that you're actively trying to fix or rectify the problem, I think they probably would come down on you a bit harder because they [the EPA] have got the power to do that. (Case A)

The manager of the organisation in Case B also suggested that there was generally little compliance with the regulations:

The EPA have that power over you and they are able to [...] I guess they are encouraging people to do the right thing. And they've been able to do it without being heavy handed. Sure, there's never been a prosecution over sewage treatment, but very few of them comply. (Case B)

This perception was also reflected in Case C, where it was suggested that monitoring and compliance were not done particularly well. This was attributed to 
the EPA being 'quite busy [...] they probably don't have the manpower'. The manager in Case $\mathrm{C}$ also demonstrated the perception that the EPA was not encouraged or supported to improve environmental performance. ' $\mathrm{I}$ ' $\mathrm{d}$ like to be more encouraged [...] if you had a bit more support'. The manager in this case suggested that environmental performance could be improved if the focus was shifted from compliance towards more encouragement and support.

There was little evidence in Cases D and E of any strong opinions concerning the EPA. The organisations in these cases did not have a lot of direct contact with the EPA, and did not give any strong indication of their perceptions of the EPA being either positive or negative.

\section{Queensland Parks and Wildlife Service}

The perceptions of QPWS were quite different from the perceptions of the EPA. The managers' perceptions of QPWS suggested a closer arrangement, whereby the actions of the QPWS had a greater effect on the organisation than those of the EPA. There was consensus that the QPWS lacked sufficient funding and staff:

\section{[...] they [QPWS] don't have enough staff. (Case A)}

Parks and Wildlife have never got any money, they've got no people to actually physically do something. (Case E)

It was suggested in Cases A, B and E that this lack of funding and limited staff had implications for the organisations:

We don't really want the areas around us to be poorly managed. So that is a concern for us, so if they're strapped for cash always you know what's going to happen to those [...] National Park areas? (Case E)

One case in particular noted a serious negative environmental outcome that could be attributed to the lack of funding and staff:

You know the greatest impact here in that area is the old National Park's toilets across the road here [...] most Monday mornings, there's raw sewage flowing out and it's [...]. It's hard to point the finger at anyone down the road and that's run by the same people who run the EPA and it's become a real issue (Case B)

Although this may be an extreme case, it does give an indication of the potential impact these issues have on organisational and environmental outcomes.

\section{The organisation-regulator relationship}

There were strong differences between the cases in the importance placed on developing and maintaining a relationship with representatives of the EPA and local QPWS rangers. Cases A and B described a strong relationship with EPA representatives, whereas the manager of the organisation in Case C suggested that they had gone out of their way to avoid developing a relationship for fear of bringing attention to issues of non-compliance. Instead, the managers in Case $\mathrm{C}$ had employed a third party as an intermediary between the EPA and the 
organisation. They suggested that this person was able to give them advice, without fear of reproach:

So he [the third party] has been great because he's been liaising with them and picking us up on things we haven't been doing but it hasn't been with any sort of policeman's role, which is good. (Case C)

Cases A, B and C all reported examples, at some stage, of grievance or dispute between their organisation and the QPWS. The managers of these organisations emphasised their efforts to rebuild relationships to promote open communication in the future and to achieve what they saw as their common interests. The time and effort that the managers invested in the development and maintenance of these relationships underscored their importance for the organisations.

Examples in Cases A and B were given:

It was a difficult relationship to create [with QPWS], because when I first arrived here, the previous manager who was here for 12 years clashed a lot. But I created a situation where we had regular meetings with them. (Case A)

We used to have a brilliant relationship with [QPWS]. You know we're all sort of the one community working to the one end. The relationship was destroyed largely because of one person. And, yeah, the relationship was really bad. It's never fully recovered. That's something you've sort of got to work at. (Case B)

This type of situation was also reflected in Case C. However, the relationship problems were also more enduring in this case:

Our first managing director, I think probably got on the wrong side of the ranger and there were a few things that, a few hassles that we had to, that have been ironed out because he's gone. (Case C)

The relationships described in Cases D and E were generally positive. The operators' relationships were described as 'fairly good' in Case D, and no grievance or dispute was identified in the interviews in either Case D or E. Although this does not necessarily imply that there has never been a dispute, it does suggest that any dispute has been inconsequential to the continued activity of the business. No attempts had been made, however, to improve the relationship and the data suggested that developing and maintaining a relationship with the regulators was not considered a priority in either of these organisations.

\section{Discussion and Conclusion}

The first research question in this study aimed to explore how tourism operators in sensitive natural environments respond to environmental regulations. Our findings suggest that there was significant variance in response even across the five case organisations that formed the sample for this study. Four of the organisations responded to environmental regulation proactively, two being classified as 'leading edge' and two as 'compliance plus', whereas one organisation exhibited a reactive response that was 'non-compliant' with the regulation (Aragón-Correa, 1998; Roome, 1992; Sharma \& Vredenburg, 1998). This finding 
is consistent with previous research that has found a broad range of organisational reactions to environmental regulations (Porter \& van der Linde, 1995a; Roome, 1992; Sharma \& Vredenburg, 1998).

Although this finding is neither remarkable nor surprising in itself, its value lies in our findings across the additional research questions where we explored the human side of environmental regulation. The results of our second research question provide further empirical support for the proposition that the perception of environmental regulation is an important variable in the relationship between environmental regulation and organisational response (Huybers \& Bennett, 1997; Sánchez, 1997).

Sánchez suggested that the perceptions of the regulation can be either positive (regulation is perceived as an opportunity) or negative (regulation is perceived as a threat). She proposed that a positive perception of the regulation would result in a more proactive or innovative organisational response. Our findings certainly support this proposition in that the two case organisations with the most positive perceptions of the regulations, Cases $\mathrm{A}$ and $\mathrm{B}$, also had the most proactive organisational responses. In contrast, Case $C$ demonstrated the most negative perception of the regulation of all three cases and also had the most reactive organisational response. Our findings also extend the propositions of Sánchez (1997) by suggesting that her propositions are likely to have more general application than just the degree of organisational innovativeness.

Our results also provide evidence that the perception of the regulatory agency is an additional variable that has an impact on the organisational response to environmental regulation. Although this variable has not been specifically identified in previous research, it is possible that it has been considered as a part of perceptions of the regulation or as part of the regulatory relationship. However, data from the five case organisations in this study suggested that it was a distinct variable.

Our results add empirical support to Fineman's $(1998,1999)$ emphasis on the importance of managing regulatory relationships, a view confirmed in other literature exploring joint environmental policy-making (Coen, 2005; Mol et al., 2000; Willman et al., 2003). In his study of the Environment Agency of England and Wales, Fineman (1998) found that the organisation-regulatory relationship played a large part in ensuring compliance and the maintenance of control. He found that regulatory inspectors' emotions and perceptions played a significant role in the quality of the relationship between the regulatory body and organisations. The findings from our study complement Fineman's research and reaffirm his proposition that organisation-regulator relationships constitute a critical variable. Our study, though, differs from Fineman's research in that it has examined environmental regulation from the perspective of the organisation, rather than the perspective of the regulatory agency. Our results therefore complement and extend previous work and indicate the importance of the regulatory relationship from the perspectives of both the organisation, as investigated in this study, and the regulator, as in Fineman's studies (1998, 1999).

Other factors mediated our case study responses, indicating that a more supportive approach to environmental regulation may be required if enduring organisation-regulator relationships are to be achieved. As an area of business 
activity, environmental tourism is highly distinctive, since the natural environment itself is the primary attraction, without which nature tourism operators would have no business. Notable differences between the case studies emerged in this regard, in terms of their orientation towards the industry and their positions within it. For example, Case A saw stronger, more comprehensive regulation as essential. On the other hand, Case $C$ was prepared to risk environmental damage in order to reduce costs. There was evidence, then, that some organisations were failing to meet basic requirements, and that they may even have little knowledge of their compliance obligations, which they saw as both costly and time-consuming.

The effects of financial constraints on both parties are evident from our case studies: going beyond compliance requires that both firms and regulators are reasonably resourced. Those organisations for whom 'flexible' regulation seems most appropriate are those for whom minimum compliance is not an issue, since (as with Case A) they identify environmental protection as integral to their own operations. These organisations were also the largest and therefore more likely to possess most discretionary resources required for improving environmental performance (Bowen, 2002). However, in order to encourage and motivate other operators, and particularly those who are non-compliant, to reach the leading edge of environmental performance our findings suggest that more support and guidance from regulators in the early stages of business operation would improve not only regulatory relationships but also environmental performance.

With the aim of building positive perceptions of both the regulation and the regulatory agency and a strong relationship, one possible course of action is suggested. The assignment of liaison officers from the regulatory agency to specific organisations or groups may help to ensure more productive organisationregulator relationships. There is also an implication inherent in this argument that the relationship benefits from reciprocity, and that organisations would benefit from being proactive in attempts to build and maintain an ongoing partnership with representatives of regulatory agencies.

Throughout the research study, every effort was made to ensure the rigour of the research. However, important limitations of this research must also be acknowledged. In the first instance, the qualitative nature of the research and the small sample size of five case organisations restricts the potential for generalisation. Although we maintain that these findings are likely to be relevant to tourism operators in sensitive natural areas in a broader region than Eastern Australia, further research would allow the broader implications of our findings to be tested.

It is also likely that the size of the organisation influences the response to environmental regulation. It is logical, for instance, that the larger the organisation the more potential environmental impact the organisation will have, and the more regulatory attention it will attract. Similarly, larger organisations are also likely to have greater capacity for allocating resources to environmental initiatives (Bowen, 2002). Further research examining this issue in more detail would be particularly valuable.

In answering our research questions, the evidence from this study suggests that there is a wide variance in how tourism operators in sensitive natural areas 
respond to environmental regulations. Our results highlight the importance of the human side of regulation and indicate the importance of three key concepts: organisations' perceptions of environmental regulation, their perceptions of the regulatory agency, and the regulatory relationship itself. The results also provide empirical support and further extend current literature on environmental regulation and highlight how organisational responses to environmental regulation can be affected by regulatory perceptions and relationships.

\section{Correspondence}

Any correspondence should be directed to Sally V. Russell, UQ Business School, The University of Queensland, Brisbane QLD 4072, Australia (s.russell@ business.uq.edu.au).

\section{References}

Allcock, A., Jones, B., Lane, S. and Grant, J. (1994) National Ecotourism Strategy. Canberra: Commonwealth Department of Tourism.

Aragón-Correa, J.A. (1998) Strategic proactivity and firm approach to the natural environment. Academy of Management Journal 41(5), 556-567.

Barbera, A. and McConnell, V. (1990) The impact of environmental regulation on industry productivity: Direct and indirect effects. Journal of Environmental Economics and Management 18, 50-65.

Bowen, F.E. (2002) Organizational slack and corporate greening: Broadening the debate. British Journal of Management 13 (4), 305-316.

Briassoulis, H. (1995) The environmental internalities of tourism: Theoretical analysis and policy implications. In H. Coccossis and P. Nijkamp (eds) Sustainable Tourism Development (pp. 25-40). Aldershot, England: Avebury/Ashgate.

Briassoulis, H., and van der Straaten, J. (1992) Tourism and the Environment: Regional, Economic and Policy Issues. Dordecht: Kluwer Academic Publishers.

Carter, R.W., Baxter, G.S., and Hockings, M. (2001) Resource management in tourism research: A new direction? Journal of Sustainable Tourism 9 (4), 265-280.

Carter, R.W., Whiley, D. and Knight, C. (2002) Improving environmental performance in the tourism accommodation sector. Paper presented at the Environment Institute of Australia, National Conference 2002: Excellence in Environmental Best Practice, Sheraton Brisbane Hotel and Towers, Brisbane 31 July-1 August.

Carter, R.W., Whiley, D. and Knight, C. (2004) Improving environmental performance in the tourism accommodation sector. Journal of Ecotourism 3 (1), 46-68.

Coen, D. (2005) Business-regulatory relations: Learning to play regulatory games in European utility markets. Governance: An International Journal of Policy, Administration, and Institutions 18 (3), 375-398.

Eisenhardt, K.M. (1989) Building theories from case study research. Academy of Management Review 14 (4), 532-550.

Elkington, J. (1994) Towards the sustainable corporation: Win-win business strategies for sustainable development. California Management Review Winter, 90-100.

Etsy, D.C. (1994) The challenge of going green. Harvard Business Review 72 (4), 41-42.

Fineman, S. (1998) Street-level bureaucrats and the social construction of environmental control. Organization Studies 19 (6), 953-974.

Fineman, S. (1999) The emotions of control: A qualitative exploration of environmental regulation. Human Relations 52 (5), 631-663.

Goodall, B., Stabler, M.J., and Stabler, M.J. (1997) Principles influencing the determination of environmental standards for sustainable tourism. In M.J. Stabler (ed.) Tourism and Sustainability: Principles to Practice (pp. 279-304). Wallingford: CABI.

Gray, R. (1994) The challenge of going green. Harvard Business Review 72 (4), 39-40.

Gray, W.B. (1987) The cost of regulation: OSHA; EPA and the productivity slowdown. The American Economic Review 77 (5), 998-1006. 
Hart, S.L. (1995) A natural-resource-based view of the firm. Academy of Management Review 20 (4), 986-1014.

Hart, S.L. (2000) Beyond greening: Strategies for a sustainable world. Harvard Business Review on Business and the Environment (pp. 105-129). Boston: Harvard Business School Publishing.

Hunt, J. and Raman, S. (2000) Regulation matters: global environmental discourse and business response. In S. Fineman (ed.) The Business of Greening. London: Routledge.

Hunter, C. (1997) Sustainable tourism as an adaptive paradigm. Annals of Tourism Research 24 (4), 850-867.

Huybers, T. and Bennett, J. (1997) The significance of the environment and its regulation to Australia's tourism industry. Australian Journal of Environmental Management 4, $40-55$.

Jaffe, A.B., Peterson, S.R., Portney, P.R. and Stavins, R.N. (1995) Environmental regulation and the competitiveness of U.S. manufacturing: What does the evidence tell us? Journal of Economic Literature 33, 132-163.

Knudsen, T. and Madsen, T.K. (2001) Improving the firm's environmental conduct: A source of competitive advantage? Journal of Strategic Marketing 9, 129-144.

Majumdar, S.K. (1997) Incentive regulation and productive efficiency in the U.S. telecommunications industry. Journal of Business 70, 547-576.

Majumdar, S.K. and Marcus, A.A. (2001) Rules versus discretion: The productivity consequences of flexible regulation. Academy of Management Journal 44 (1), 170-179.

Maxwell, J.W. (1996) What to do when win-win won't work: Environmental strategies for costly regulation. Business Horizons 39, 60-63.

Miles, M.B. and Huberman, A.M. (1984) Qualitative Data Analysis: A Sourcebook of New Methods. Beverly Hills: Sage Publications.

Mitchell, R. and Bernauer, T. (1998) Empirical research on international environmental policy: Designing qualitative case studies. Journal of Environment and Development 7 (1), 4-31.

Mol, A., Lauber, V. and Liefferink, D. (2000) The Voluntary Approach to Environmental Policy. Oxford: Oxford University Press.

Porter, M.E. and van der Linde, C. (1995a) Green and competitive: Ending the stalemate. Harvard Business Review 73 (5), 120-134.

Porter, M.E. and van der Linde, C. (1995b) Toward a new conception of the environmentcompetitiveness relationship. Journal of Economic Perspectives 9 (4), 97-118.

Roome, N. (1992) Developing environmental managment systems. Business Strategy and the Environment 1 (1), 11-24.

Rosen, C.M. (2001) Environmental strategy and competitive advantage: An introduction. California Management Review 43 (3), 8-16.

Sánchez, C.M. (1997) Environmental regulation and firm-level innovation. Business and Society 36 (2), 140-168.

Sharma, S. and Vredenburg, H. (1998) Proactive corporate environmental strategy and the development of competitively valuable organizational capabilities. Strategic Management Journal 19, 729-753.

van Fossen, A. and Lafferty, G. (2001) Contrasting models of land use regulation: Community, government and tourism development. Community Development Journal 36 (3), 198-211.

Weitzman, M.L. (1974) Prices vs. quantities. Review of Economic Studies 41, 477-491.

Wells, R.P. (1994) The challenge of going green. Harvard Business Review 72 (4), 43-44.

Willman, P., Coen, D., Currie, D. and Siner, M. (2003) The evolution of regulatory relationships; regulatory institutions and firm behaviour in privatized industries. Industrial and Corporate Change 12 (1), 69-89.

Yin, R.K. (2003) Case Study Research: Design and Methods (3rd edn). Thousand Oaks: Sage Publications.

Yunis, E. (2003) Sustainable tourism: World trends and challenges ahead. In R. Buckley, C. Pickering and D. Weaves (eds) Nature-Based Tourism, Environment and Land Management. Wallingford: CABI Press. 